\title{
A highly divergent Encephalomyocarditis virus isolated from nonhuman primates in Singapore
}

Dawn Su-Yin Yeo ${ }^{1}$, Jing Er Lian², Charlene J Fernandez ${ }^{3}$, Yueh-Nuo Lin³ ${ }^{3}$ Jasper Chin-Wen Liaw ${ }^{1}$, Moi-Lien Soh³, Elizabeth Ai-Sim Lim ${ }^{1}$, Kwai-Peng Chan ${ }^{4}$, Mah-Lee $\mathrm{Ng}^{5}$, Hwee-Cheng Tan ${ }^{6}$, Serena Oh7, Eng-Eong Ooi ${ }^{6}$ and Boon-Huan Tan ${ }^{1,8,9^{*}}$

\begin{abstract}
Background: In 2001 and 2002, fatal myocarditis resulted in the sudden deaths of four, two adult and two juvenile, orang utans out of a cohort of 26 in the Singapore Zoological Gardens.

Methods: Of the four orang utans that underwent post-mortem examination, virus isolation was performed from the tissue homogenates of the heart and lung obtained from the two juvenile orang utans in Vero cell cultures. The tissue culture fluid was examined using electron microscopy. Reverse transcription and polymerase chain reaction with Encephalomyocarditis virus (EMCV)-specific primers targeting the gene regions of VP3/VP1 and 3D polymerase (3Dpol) confirmed the virus genus and species. The two EMCV isolates were sequenced and phylogenetic analyses of the virus genes performed. Serological testing on other animal species in the Singapore Zoological Gardens was also conducted.

Results: Electron microscopy of the two EMCV isolates, designated Sing-M100-02 and Sing-M105-02, revealed spherical viral particles of about 20 to $30 \mathrm{~nm}$, consistent with the size and morphology of members belonging to the family Picornaviridae. In addition, infected-Vero cells showed positive immunoflorescence staining with antiserum to EMCV. Sequencing of the viral genome showed that the two EMCV isolates were $99.9 \%$ identical at the nucleotide level, indicating a similar source of origin. When compared with existing EMCV sequences in the VP1 and $3 \mathrm{Dpol}$ gene regions, the nucleotide divergence were at a maximum of $38.8 \%$ and $23.6 \%$ respectively, while the amino acid divergence were at a maximum of $33.9 \%$ and $11.3 \%$ respectively. Phylogenetic analyses of VP1 and 3Dpol genes further grouped the Sing-M100-02 and Sing-M105-02 isolates to themselves, away from existing EMCV lineages. This strongly suggested that Sing-M100-02 and Sing-M105-02 isolates are highly divergent variants of EMCV. Apart from the two deceased orang utans, a serological survey conducted among other zoo animals showed that a number of other animal species had neutralizing antibodies to Sing-M105-02 isolate, indicating that the EMCV variant has a relatively wide host range.
\end{abstract}

Conclusions: The etiological agent responsible for the fatal myocarditis cases among two of the four orang utans in the Singapore Zoological Gardens was a highly divergent variant of EMCV. This is the first report of an EMCV infection in Singapore and South East Asia.

Keywords: Encephalomyocarditis virus, Variant virus, Fatal acute myocarditis, Orang utan

\footnotetext{
* Correspondence: EPHTBH@nus.edu.sg

'Defence Medical and Environmental Research Institute, DSO National

Laboratories, \#13-00, 27 Medical Drive, Buona 117510, Singapore

${ }^{8}$ Saw Swee Hock School of Public Health, National University of Singapore,

Singapore, Singapore

Full list of author information is available at the end of the article
} 


\section{Introduction}

Between July 2001 and January 2002, four (3 Bornean, Pongo pygmaeus and 1 Sumatran, Pongo abelii) orang utans, two (male and female) adults and two (male and female) juveniles, from a cohort of 26 in the Singapore Zoological Gardens died suddenly. Post-mortem examination of the four orang utans revealed pathology characterized by multifocal myocarditis, pulmonary congestion and edema, hydropericardium, hydrothorax and Ascites.

A literature review revealed several reports describing Encephalomyocarditis virus (EMCV) as the etiological agent of viral myocarditis in captive primates. These primates included semi-wild bonobos [1], baboons [2], chimpanzees [3], lemurs [4], rhesus macques [5], and orang utans $[3,6]$. EMCV infection was also implicated in the deaths of various animals in Audubon Park Zoo, New Orleans, in 1985 [7]; and in elephants in a Florida zoo in 1997 [8]. Outside the United States, sporadic outbreaks of EMCV involving a variety of zoo animals had occurred in Taronga Zoo in Australia from 1987 to 1995 [3]; in free-living elephants in Kruger National Park, South Africa between 1993 and 1994 [9,10]; and in an Italian zoo affecting 15 different primates between 2006 and 2008 [4]. In addition, EMCV infections were reported in Russia from monkeys bred from the Sukhumi Breeding Center in 1974; and in the Adler Breeding Center, since 2001 [11]. EMCV has also been recognized as a porcine pathogen, with EMCV infections in European pigs associated with sudden deaths and reproductive failure [12-16]. In Asia, EMCV was isolated from pigs in South Korea and implicated as the cause of reproductive failure in pigs in Taiwan $[17,18]$. Apart from EMCV, there has been one other report describing Coxsackie virus B4 as the etiological cause of fatal myocarditis in a female orang utan at the Okinawan Zoo in 1999 [19].

Although the potential for EMCV to cross the species barrier has been demonstrated as seen from the various zoo outbreaks described above, human cases have fortunately been rare. Sporadic human EMCV infections and disease have been documented by virus isolation from different specimen types such as serum, stool samples, cerebrospinal fluid and throat washings [20,21]. A recent study describing the etiology of acute febrile disease in locations across South America concluded that there is evidence supporting a role for EMCV in human infection and febrile illness [22]. However, the extent of the effect of EMCV on human health is still largely unknown because the disease is so infrequent in humans.

We hypothesized that the etiological agent behind the deaths of the orang utans in the Singapore Zoological Gardens was either a Coxsackie virus B, or more likely, an EMCV. Although both viruses are members of the same family, Picornaviridae [23], they belong to different genera as Coxsackie virus B is an Enterovirus, and
EMCV, a Cardiovirus. The Picornaviridae family is one of the largest and most diverse families of RNA viruses, and includes etiological agents that are responsible for a wide variety of human and animal diseases [23].

The picornavirions are small, non-enveloped and spherical, with a diameter of about 20 to $30 \mathrm{~nm}$. Picornaviruses have a single-stranded, positive sense RNA genome that is between 7.2 and $9 \mathrm{~kb}$ in length and contain a large opening reading frame (ORF). The ORF encodes for a polyprotein that comprises both non-structural and structural elements divided into three primary precursor molecules, namely P1, P2 and P3, encoding for 11 distinct proteins. The structural proteins VP4, VP2, VP3 and VP1 make up the viral capsid and are encoded in the P1 region towards the $5^{\prime}$-end of the genome. Non-structural proteins are derived from the P2 and P3 regions and are encoded towards the 3 '-end of the genome, the largest of which is the RNA-dependent RNA polymerase (3Dpol). In addition, cardioviruses code for an L (Leader) protein at the $\mathrm{N}$-terminus of their polyproteins. The genomic RNA also contains a highly structured $5^{\prime}$-UTR (untranslated region) that includes an internal ribosome entry site (IRES) from which viral protein translation is initiated in a cap-independent manner. The shorter 3'-UTR terminates with a heterogeneous poly(A) tail that is known to be involved in the binding process of the viral replicase complex.

In this paper, we described the cell culture isolation and identification of two viral isolates obtained postmortem from the two juvenile Bornean orang utans. The viral genomes of the two isolates were $>95 \%$ sequenced, with the complete genome sequence lacking about 200 nucleotides (nt) from the $5^{\prime}$ end. Phylogenetic and sequence analyses suggested that the newly isolated viruses are highly divergent variants of EMCV and possibly a new serotype of the virus. This is the first report of EMCV infection in Singapore and South East Asia and its molecular characterization.

\section{Results}

\section{Virus isolation and preliminary diagnosis}

Virus isolates, designated Sing-M105-02 and Sing-M100-02, were successfully isolated in African Green Monkey kidney (Vero) cells from the heart tissues of the first juvenile orang utan, and lung tissues of the second autopsied juvenile orang utan, respectively. Cytopathic effect (CPE) was observed in Vero cells inoculated with the heart homogenate, at 2 days post-infection (pi). Infected-Vero cells were distorted from its normal shape, became granular and finally rounded-up (results not shown). Similar observations of CPE were made with the inoculation of lung homogenate at 3 days pi. Uninfected Vero cells did not show any signs of CPE. Both virus isolates were also inoculated into Mardin Darby Canine Kidney (MDCK) cells (data not shown). At 1 to 2 days 


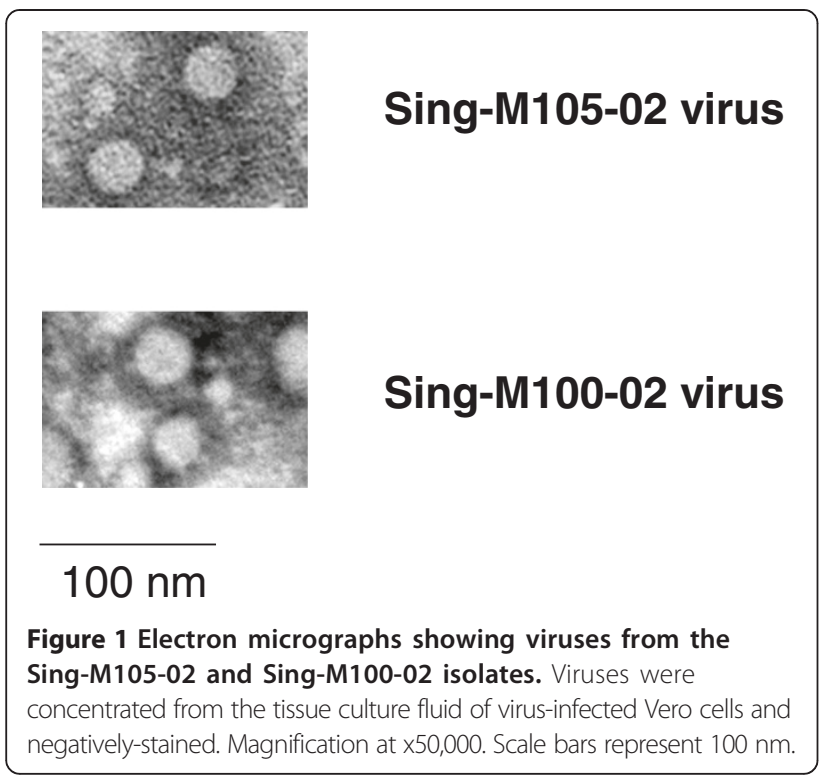

pi, CPE in virus infected-MDCK cells was characterized by rounded and wrinkled appearances.

The viruses in infected-Vero tissue culture fluid were negatively stained and examined with electron microscopy. The electron micrographs revealed numerous small round virus particles with smooth appearances in the range of 20 to $30 \mathrm{~nm}$ for both Sing-M105-02 and Sing-M100-02 isolates (Figure 1). The morphology and size observed are consistent with virus members belonging to the family of Picornaviridae [23].

A second passage of the virus isolates in Vero cells resulted in rapid and advanced CPE a day after inoculation. Sing-M105-02 (Figure 2a) and Sing-M100-02 (Figure 2b) virus-infected Vero cells reacted to polyclonal antiserum raised to EMCV with specific green and yellow fluorescence staining in the cytoplasm. The perinuclear regions were stained more intensely. These results were consistent with observations made for EMCV(Aust)-infected Vero cells (Figure 2c), indicating that the Sing-M105-02 and Sing-M100-02 viruses could be EMCV. Cytoplasmic areas appeared red with counter stain Evans Blue, and no green fluorescence was observed in uninfected Vero cells (Figure 2d).

\section{Virus identification and full-genome molecular characterization}

Viral RNA, extracted from the virus-infected tissue culture fluid, was subjected to RT-PCR analysis using one set of primers that were specific for enterovirus detection $[24,25]$, while another two sets of primers specific for the detection of EMCV were also used [13,26] (Table 1). No products were detected from the enterovirus RT-PCR, while approximately $855 \mathrm{bp}$ and 286 bp products were observed with the VP3/VP1 and 3Dpol primer sets respectively for both Sing-M105-02 and Sing-M100-02 viruses (results not shown). The sizes were consistent with
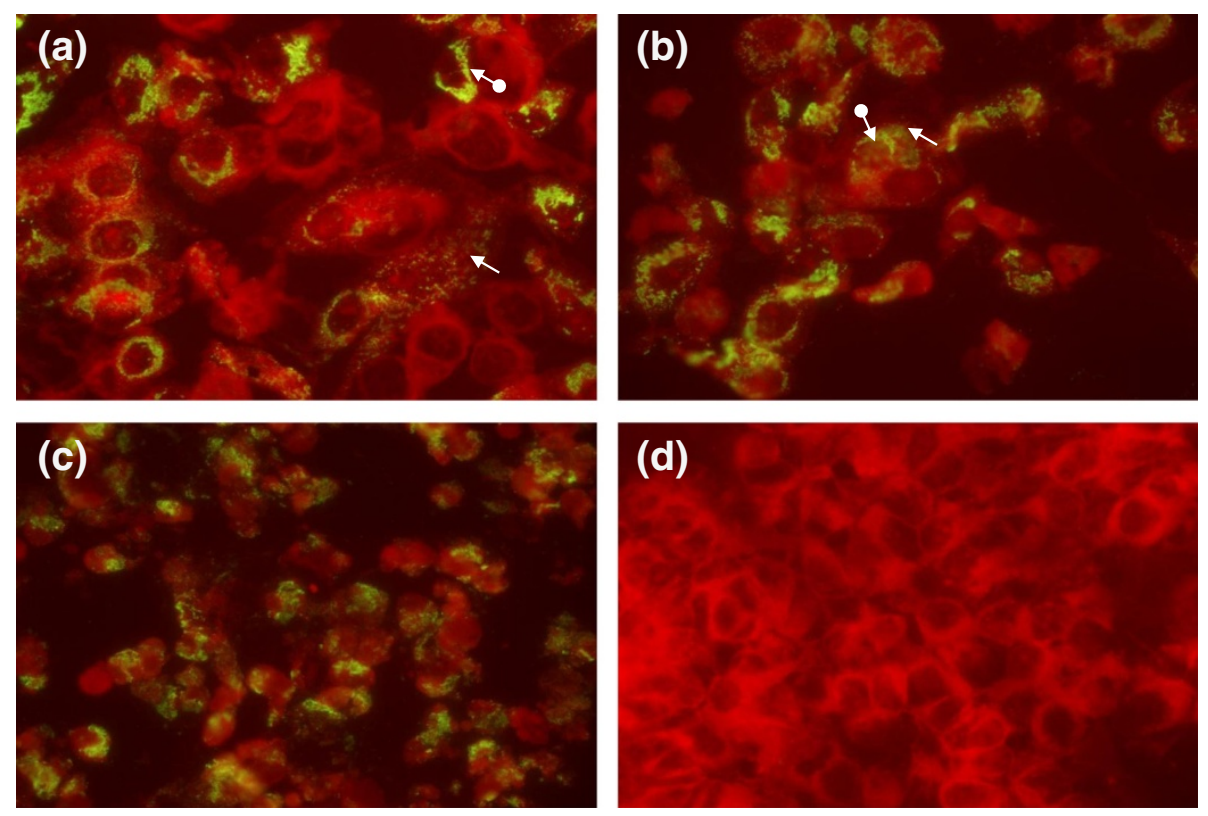

Figure 2 Immunoflorescence staining of Vero cells infected with (a) Sing-M105-02 isolate, (b) Sing-M100-02 isolate, and (c) EMCV(Aust) strain. The infected cells were allowed to react with porcine polyclonal antibodies raised against EMCV. The virus-infected Vero cells stained greenish yellow in the cytoplasm $(\longrightarrow$ ), and at the perinuclear region $(\longrightarrow)$, indicating the presence of virus antigens. (d) Uninfected Vero cells stained red with counter stain. Magnification at x60. 
Table 1 Sequences and references for primers used for RT and PCR reactions

\begin{tabular}{|c|c|c|c|c|}
\hline Virus designation & Primer names and sequences ( $5^{\prime}$ to $\left.3^{\prime}\right)$ & Gene target & Amplicon size & References \\
\hline \multirow[t]{2}{*}{ EMCV } & $\mathrm{P} 1=\mathrm{CCC}$ TAC CTC ACG GAA TGG GGC AAA G & 3D polymerase gene & $286 \mathrm{bp}$ & [13] \\
\hline & $\mathrm{P} 2=\mathrm{GGT}$ GAG AGC AAG CCT CGC AAA GAC AG & & & \\
\hline \multirow[t]{2}{*}{ EMCV } & $\mathrm{P} 9=\mathrm{ATC}$ AAG ACT CCA GCT CTC GGG GTC A & VP3NP1 capsid gene & $855 \mathrm{bp}$ & {$[26]$} \\
\hline & $\mathrm{P} 10=\mathrm{TGC}$ CTA TCT CAC CTG CCC CCT GGA G & & & \\
\hline \multirow[t]{2}{*}{ Enterovirus } & RotbartFor = CCT CCG GCC CCT GAA TGC GGC TAAT & $5^{\prime}$ non-coding region & $153 \mathrm{bp}$ & [25] \\
\hline & RotbartRev = ACC GAC GAA TAC CAC TGT TA & & & \\
\hline \multirow[t]{2}{*}{ Enterovirus } & $\mathrm{EV} 2=\mathrm{TCC}$ GGC CCC TGA ATG CGG CTA ATC C & $5^{\prime}$ non-coding region & $113 \mathrm{bp}$ & {$[24]$} \\
\hline & $\mathrm{EV} 1=\mathrm{ACA} C \mathrm{CG}$ ACA CCC AAA GTA GTC GGT CC & & & \\
\hline
\end{tabular}

reports using the same primer sets [26-28]. No results were observed on RT-PCR performed on sample processed from uninfected Vero cells or when water was used to replace the viral RNAs. All the PCR assays were repeated at low stringency so as to detect potentially related viruses. The RT-PCR results indicated that Sing-M105-02 and
Sing-M100-02 isolates belong to Cardiovirus genus and to EMCV species.

We managed to sequence more than $95 \%$ of the full virus genome (i.e. $\sim 7.6 \mathrm{~kb}$ ) of both Sing-M105-02 and Sing-M100-02 isolates by primer walking (Table 2). This included the entire ORF and 3 '-UTR of the virus. Despite

Table 2 Primers used for RT-PCR and sequencing of Sing-M105-02 and Sing-M100-02 virus isolates

\begin{tabular}{|c|c|c|c|c|}
\hline Primer designation & Sequence $\left(5^{\prime}\right.$ to $\left.3^{\prime}\right)$ & $\begin{array}{c}\text { Nucleotide position } \\
\text { (estimated) }\end{array}$ & Forward/Reverse & Primer reference \\
\hline EMCVF445 & TTTGCAGGCAGCGGAATC & 490 & Forward & This study \\
\hline M105R524 & CGTGCCGCCTTTGCAGGTGTCTG & 524 & Reverse & This study \\
\hline M105R870 & CCATTTCTGTATTGCAGGGCAGAGC & 870 & Reverse & This study \\
\hline EMCVF1070 & TAATGCAGCCGGGTCTGACC & 1070 & Forward & This study \\
\hline M105R2369 & CAAAATAACTGAGTTTGGAC & 2369 & Reverse & This study \\
\hline EMCV2737R & GCTACAAAATCTGGAGTAGCA & 2689 & Reverse & This study \\
\hline EMCV-P10 & TGCCTATCTCACCTGCCCCCTGGAG & 2674 & Forward & {$[26]$} \\
\hline M105R2843 & ACTGTGGTCCTGGTGTCA & 2800 & Reverse & This study \\
\hline M105VP1F419 & AATCATGGCTTAGCTG & 3000 & Forward & This study \\
\hline M105VP1F540 & CCGGAACCTCAAACCA & 3200 & Forward & This study \\
\hline M105VIPR768 & ACAGTAGGTCTCGGACA & 3354 & Reverse & This study \\
\hline EMCV-P9 & ATCAAGACTCCAGCTCTCGGGGTCA & 3529 & Reverse & {$[26]$} \\
\hline M105Middle-F505 & AACCCGTGGAAGAGAACCT & 3710 & Forward & This study \\
\hline EMC-2B65R & TCGGCAGTAGGGTTTGAG & 3975 & Reverse & {$[26]$} \\
\hline M105F4204 & ATTGCAGGAATGACAATT & 4200 & Forward & This study \\
\hline M105Contiq3-R335 & AGTTGCAGGGTTITGGTG & 5500 & Reverse & This study \\
\hline M105Contiq3-F327 & CCTGCAACTGCTGGATGT & 5839 & Forward & This study \\
\hline M105F5906 & ACAGGAAAAGATACCGATGT & 5980 & Forward & This study \\
\hline M105R6000 & TAATGGTCCTGAATTAAG & 6000 & Reverse & This study \\
\hline M105R6500 & ATCGAATTTAGACAACACTGC & 6500 & Reverse & This study \\
\hline M105POLF16 & ACACTAGATGATGTAGTTT & 7000 & Forward & This study \\
\hline M105POLR158 & GTCACTGAGGTGAGTT & 7460 & Reverse & This study \\
\hline EMCV-P1 & CCCTACCTCACGGAATGGGGCAAAG & 7631 & Reverse & [13] \\
\hline EMCV-P2 & GGTGAGAGCAAGCCTCGCAAAGACAG & 7370 & Forward & [13] \\
\hline
\end{tabular}


numerous attempts to amplify out the $5^{\prime}$-UTR region, we were unable to obtain about $200 \mathrm{nt}$ of virus sequence from the $5^{\prime}$ end of the genome, including the poly $(\mathrm{C})$ tract. This difficulty in sequencing the $5^{\prime}$-UTR region was also reported for another EMCV strain [29], possibly due to the high GC content and complex secondary structure in this region. The Sing-M105-02 and Sing-M100-02 isolates showed a high sequence identity of $99.9 \%$ in the entire ORF (Tables 3 and 4), indicating that both viruses represent separate isolates of a single virus strain, probably originating from a similar source.

\section{Sequence comparison with existing EMCV strains}

To investigate the genetic relationship of Sing-M105-02 and Sing-M100-02 isolates with existing cardioviruses (EMCV and Theiloviruses), we performed sequence comparison for the entire ORF, VP1 capsid and 3Dpol gene regions. Table 3 reflects the percent nt and deduced

Table 3 Percent nucleotide (nt) and deduced amino acid (aa) identities of the entire ORF, VP1 and 3Dpol genes of Sing-M105-02 compared to Sing-M100-02, other EMCV and The ilovirus strains (all members of the Cardiovirus genus)

\begin{tabular}{|c|c|c|c|c|c|c|c|}
\hline & \multirow[b]{2}{*}{ Virus strain } & \multicolumn{2}{|c|}{ ORF } & \multicolumn{2}{|c|}{ VP1 } & \multicolumn{2}{|c|}{ 3Dpol } \\
\hline & & nt & aa & nt & aa & nt & aa \\
\hline \multirow[t]{25}{*}{ EMCV } & Sing-M100-02 & 99.9 & 99.9 & 99.9 & 99.6 & 100.0 & 100.0 \\
\hline & EMCV D (M22458) & 75.2 & 86.3 & 73.6 & 86.3 & 78.4 & 88.9 \\
\hline & EMCV B (M22457) & 75.1 & 86.3 & 73.5 & 86.3 & 78.4 & 89.8 \\
\hline & EMCV D (M37588) & 75.3 & 86.4 & 73.5 & 86.3 & 78.6 & 89.8 \\
\hline & EMCV PV2 (X87335) & 75.3 & 86.4 & 73.4 & 85.9 & 78.6 & 89.8 \\
\hline & EMCV G424-90 (AJ617362) & \multicolumn{2}{|c|}{ NA } & 73.3 & 85.2 & \multicolumn{2}{|c|}{ NA } \\
\hline & EMCV pEC9 (DQ288856) & 75.5 & 86.6 & 73.3 & 87.0 & 79.2 & 88.9 \\
\hline & EMCV BEL-288791 (AF356822) & 75.6 & 86.7 & 73.2 & 86.6 & 79.2 & 89.8 \\
\hline & EMCV CBNU (DQ517424) & 75.6 & 86.7 & 73.2 & 86.3 & 79.2 & 88.7 \\
\hline & EMCV GX0601 (FJ604852) & 75.5 & 86.6 & 73.2 & 86.6 & 79.1 & 89.6 \\
\hline & EMCV Mengo M (L22089) & 75.5 & 86.6 & 73.2 & 87.0 & 78.6 & 88.7 \\
\hline & EMCV Mengo Rz-pMwt (DQ294633) & 75.5 & 86.6 & 73.2 & 87.0 & 78.6 & 89.8 \\
\hline & EMCV pV21 (X74312) & 75.5 & 86.5 & 73.2 & 86.3 & 79.3 & 89.6 \\
\hline & EMCV GX0602 (FJ604853) & 75.4 & 86.4 & 73.0 & 86.6 & 78.9 & 89.6 \\
\hline & EMCV HB1 (DQ464063) & 75.5 & 86.6 & 73.0 & 86.6 & 79.2 & 89.8 \\
\hline & EMCV K11 (EU780149) & 75.5 & 86.6 & 73.0 & 86.3 & 79.2 & 89.3 \\
\hline & EMCV K3 (EU780148) & 75.5 & 86.3 & 73.0 & 85.9 & 79.1 & 88.7 \\
\hline & EMCV BJC3 (DQ464062) & 75.5 & 86.6 & 72.9 & 86.3 & 79.2 & 89.8 \\
\hline & EMCV GXLC (FJ897755) & 75.5 & 86.4 & 72.9 & 85.2 & 79.0 & 89.8 \\
\hline & EMCV R (M81861) & 75.4 & 86.2 & 72.8 & 85.6 & 79.1 & 90.2 \\
\hline & EMCV Ruckert (M81861) & 75.4 & 86.2 & 72.8 & 85.6 & 79.1 & 89.6 \\
\hline & EMCV MN-30 (AY296731) & 75.1 & 86.4 & 72.4 & 86.6 & 78.6 & 89.8 \\
\hline & EMCV 1086C (DQ835185) & 74.6 & 86.9 & 71.8 & 87.0 & 76.4 & 88.7 \\
\hline & EMCV C108-95 (AJ617359) & \multicolumn{2}{|c|}{ NA } & 71.1 & 87.0 & \multicolumn{2}{|c|}{ NA } \\
\hline & EMCV RD1338 (JX257003) & 73.6 & 82.5 & 61.2 & 66.1 & 80.9 & 89.6 \\
\hline \multirow[t]{7}{*}{ Theilovirus } & SAFV-1 (EF165067).seq & 56.7 & 53.6 & 77.4 & 88.6 & 60.8 & 53.5 \\
\hline & SAFV-2 (AM922293).seq & 57.1 & 54.0 & 75.0 & 85.9 & 57.5 & 52.8 \\
\hline & TMEV BeAn 8386 (M16020).seq & 57.3 & 54.8 & 75.3 & 83.9 & 58.5 & 51.0 \\
\hline & TMEV BeAn 8386 S2 (DQ401688).seq & 57.3 & 54.9 & 75.5 & 83.9 & 58.7 & 51.0 \\
\hline & TMEV DA (M20301).seq & 57.1 & 55.1 & 75.5 & 81.8 & 60.4 & 50.6 \\
\hline & TMEV GDVII (M20562).seq & 57.7 & 55.0 & 71.5 & 78.9 & 58.1 & 50.6 \\
\hline & TMEV GDVII (X56019).seq & 57.7 & 55.0 & 71.5 & 78.9 & 57.9 & 50.2 \\
\hline
\end{tabular}


Table 4 Percent nucleotide identity of the L protein, P1 capsid, P2 non-structural, P3 non-structural and 3'UTR regions of Sing-M105-02 compared to Sing-M100-02 and other EMCV strains

\begin{tabular}{lcccccc}
\hline Virus strain & Proposed lineage & L & P1 & P2 & P3 & 3' UTR \\
\hline Sing-M100-02 & D & 100.0 & 99.9 & 99.9 & 100.0 & 100.0 \\
EMCV Ruckert (M81861) & & 79.1 & 75.6 & 74.9 & 74.8 & 84.1 \\
EMCV pV21 (X74312) & & 79.1 & 75.6 & 74.7 & 75.0 & 85.7 \\
EMCV PV2 (X87335) & $\mathrm{A}$ & 80.1 & 74.9 & 75.4 & 74.8 & 85.6 \\
EMCV B (M22457) & & 79.1 & 74.9 & 75.1 & 74.7 & 74.7 \\
EMCV D (M22458) & & 80.1 & 75.0 & 75.1 & 85.4 \\
EMCV Mengo M (L22089) & $\mathrm{C}$ & 81.6 & 76.1 & 74.5 & 74.9 & 87.9 \\
EMCV 1086C (DQ835185) & $\mathrm{B}$ & 86.1 & 75.5 & 73.1 & 73.3 & $\mathrm{NA}$ \\
EMCV RD1338 (JX257003) & $\mathrm{E}$ & 80.1 & 67.7 & 76.4 & 77.3 & 81.2 \\
\hline
\end{tabular}

The proposed EMCV lineage is also indicated. The virus strains names are shown followed by the GenBank accession number in brackets. NA indicates sequence data not available.

amino acid (aa) identities of the entire ORF, VP1 capsid and 3Dpol gene regions for Sing-M105-02 and SingM100-02 isolates compared with other fully sequenced Cardiovirus strains. In the conserved 3Dpol region, the extent of sequence identities between the Sing-M100-02 and Sing-M105-02 isolates and other EMCV strains ranged from $76.4 \%$ to $80.9 \%$ (nt level) and $79.4 \%$ to $90.5 \%$ (aa level). The lowest sequence relationships were observed in the variable VP1 capsid region, with percent identities ranging from $61.2 \%$ to $73.6 \%$ (nt level) and $66.1 \%$ to $87.0 \%$ (aa level). Table 4 compares the relationship of the SingM105-02 and Sing-M100-02 isolates against selected fully sequenced EMCV strains in the different coding regions across the entire ORF (namely L, P1, P2 and P3), and also the 3 '-UTR region. We note that nt sequence identities were all below $80 \%$ in the P1, P2 and P3 regions between our isolates and existing EMCV strains, once again demonstrating the high divergence of the Sing-M105-02 and Sing-M100-02 isolates.

The aa sequence alignment of the P1 structural region was next examined and we observed significant differences in the BC-loop and loop I regions in the VP1 capsid of the Sing-M105-02 and Sing-M100-02 isolates with other EMCV strains (see boxed region in Figure 3). The BCloop and loop I regions of the VP1 capsid protein are two putative neutralizing antigenic sites proposed in the EMCV Mengo virus strain [30,31]. Taken together, our sequence data indicated that the Sing-M105-02 and Sing-M100-02 isolates have a highly divergent nature compared to any known strains of EMCV.

\section{Phylogenetic analysis}

We included fully sequenced EMCV and Theilovirus strains in our phylogenetic trees to demonstrate the divergence of the 2 species in the genus Cardiovirus, as well as to emphasize the diversity and clustering of various EMCV strains (Figure 4). Our phylogenetic analyses showed branching of the EMCV strains into four main lineages, A, B, C and D, at the nt level in the VP1 and $3 \mathrm{Dpol}$ regions, as well as for the entire ORF (Figure 4). Lineages $\mathrm{A}, \mathrm{B}$ and $\mathrm{C}$ concurred with similar clusterings of EMCV strains as described previously [10,26,32]. However, the Sing-M105-02 and Sing-M100-02 viruses clustered separately as a distinct group by themselves in lineage D (Figure 4). A recent report of a second serotype of EMCV, isolate RD1338 [29], also clustered by itself in lineage E, highly distinct from the Sing-M105-02 and Sing-M100-02 viruses (lineage D) and other EMCV in lineages A, B and C. Our phylogenetic studies further demonstrated that Sing-M105-02 and Sing-M100 viruses are highly divergent strains of EMCV.

\section{Serological survey of the zoo animals}

In order to investigate whether other zoo animals had been exposed to the EMCV variant, a serological survey was conducted. Sera were collected from a variety of zoo animals, in particular animals residing near the orang utans, and titrated for neutralizing antibodies to both Sing-M105-02 virus and EMCV(Aust). A selection of capybaras (80\%), chimpanzees (31\%) and orang utans (50\%) exhibited neutralizing antibody titers to Sing-M105-02 virus, strongly indicating that they had been exposed to the virus (Table 5). In total, 22 of 122 zoological animals (18\%) exhibited neutralizing antibody titers to the SingM105-02 isolate. All of the chimpanzees, except one, and an orang utan also had high neutralizing antibody titer to EMCV(Aust) (results not shown). Our serological survey indicated that there may have been two strains of EMCV circulating among the zoo animals. One of the viruses could be an EMCV, closely related to EMCV (Aust), although no attempts at virus isolation were made from these exposed animals. The second virus could be a variant of the EMCV, similar to Sing-M105-02 and Sing-M100-02.

As previous reports have implicated rodents in the initiation of EMCV outbreaks, a rodent control program 


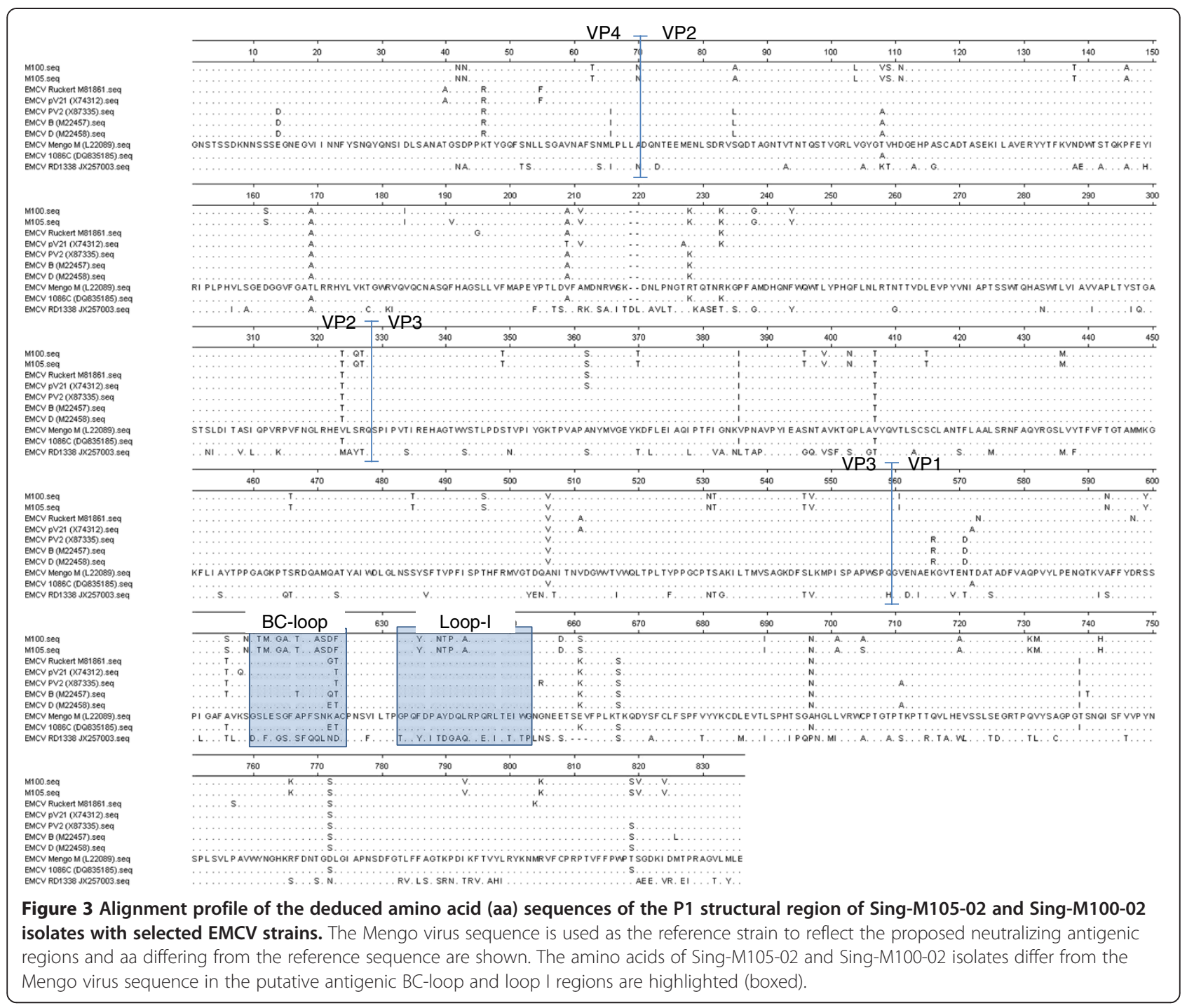

was initiated at the Singapore Zoological Gardens as a control measure for the management of the myocarditis outbreak [33]. However, only two rats were caught, and these were bled. The two rats were sampled and demonstrated high titers of neutralizing antibodies to SingM105-02 virus (Table 5); one of the rats had neutralizing antibody to both Sing-M105-02 virus and EMCV(Aust) (results not shown). Our data provided evidence that the rats were exposed to either the Sing-M105-02 virus, or both the Sing-M105-02 virus and another EMCV.

\section{Discussion}

The virus outbreak in the Singapore Zoological Gardens took place over an estimated period of 8 months, and occurred in orang utans of various ages, as well as sporadically among other zoo animals. This is the first report of an EMCV infection in Singapore. There were altogether four deaths in the orang utan cohort, caused by acute myocarditis. Other animals, two zebras, one spider monkey, one guanaco, and two capybaras also died of similar clinical signs. One adult orang utan displayed respiratory problems but recovered with intensive supportive therapy.

From the two juvenile orang utans that died, viruses were isolated successfully from the heart (designated SingM105-02) and lung (designated Sing-M100-02) homogenates in Vero cells. Virus isolation was not performed on the two autopsied adult orang utans. The viral agents isolated in Vero cells were examined under transmission electron microscopy and the viruses showed similar morphology to the picornaviruses (Figure 1). In addition, virus-infected Vero cells showed positive immunofluorescence to polyclonal antiserum raised to EMCV (Figure 2). 


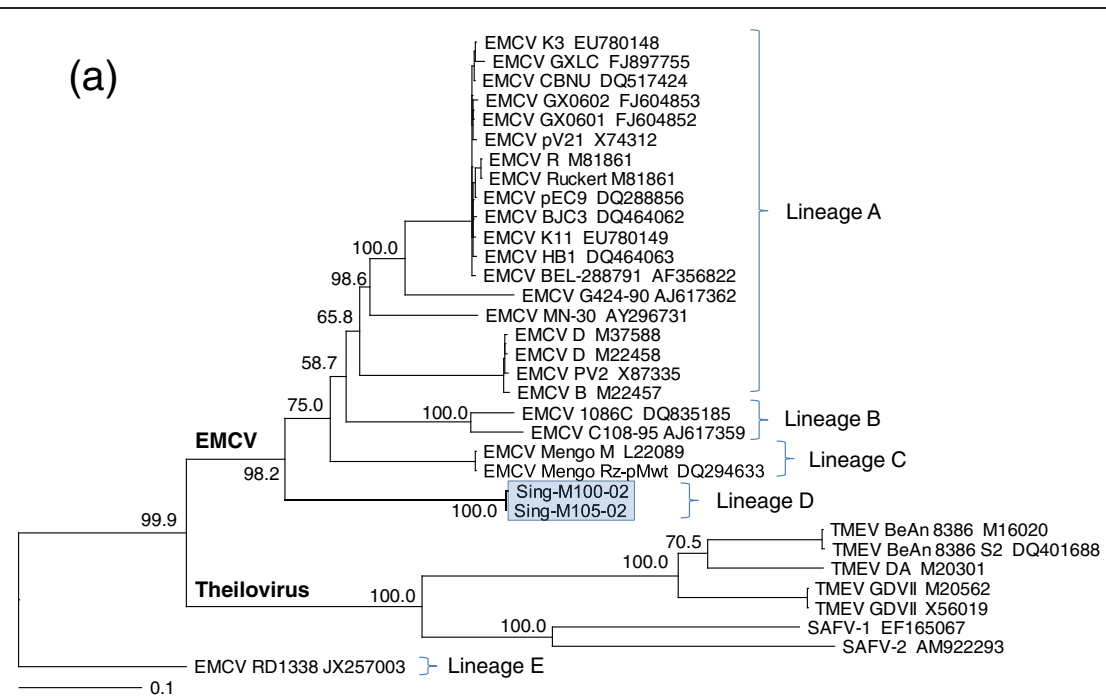

(b)
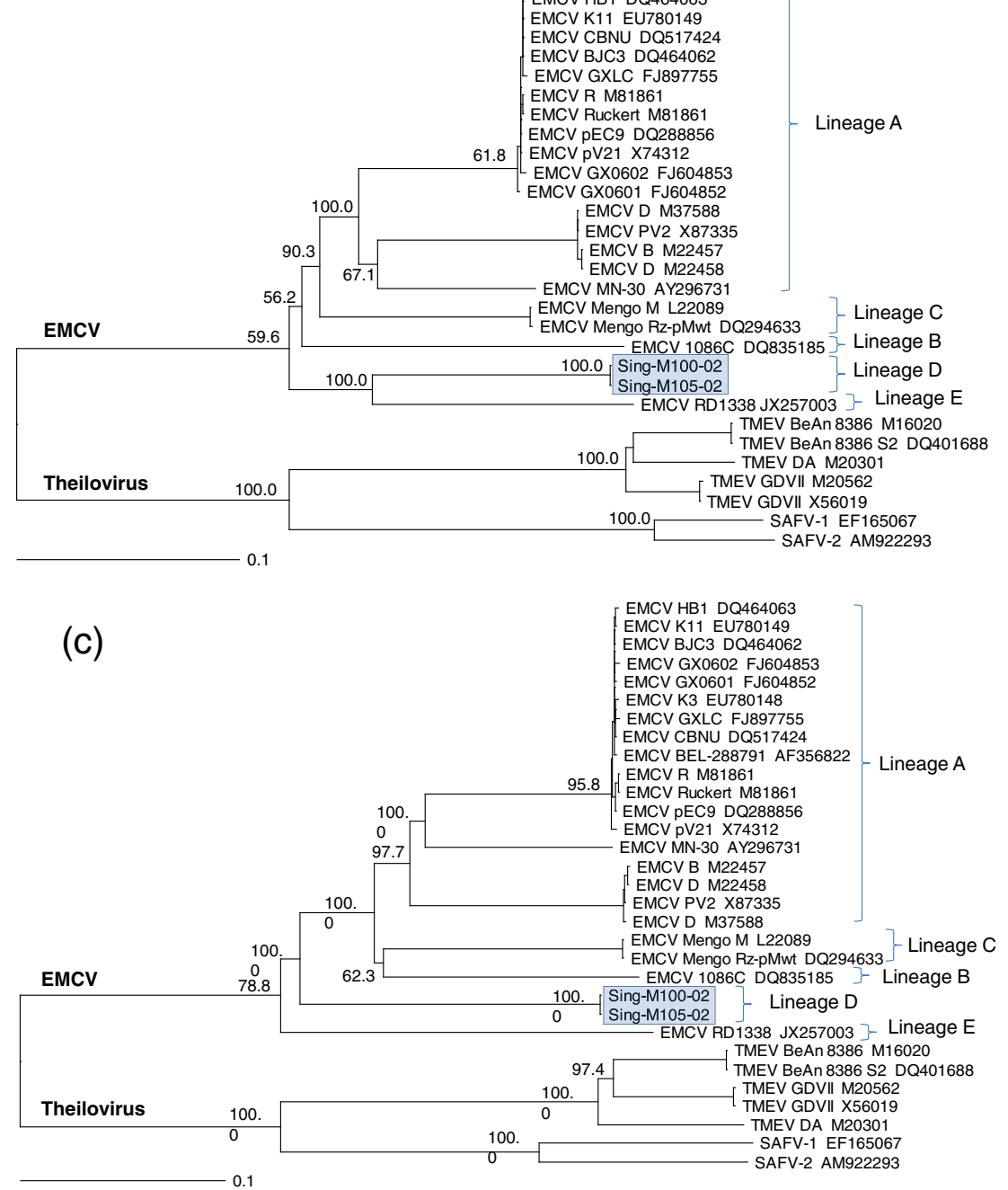

Figure 4 (See legend on next page.) 
(See figure on previous page.)

Figure 4 Phylogenetic trees of the full genes of the (A) VP1 capsid, (B) 3D polymerase (3Dpol), and (C) open reading frame (ORF) of Encephalomyocarditis viruses (EMCV) and Theiloviruses based on their nucleotide sequence. Isolate names are followed by their GenBank accession number. The EMCV isolates generated in this study, Sing-M100-02 and Sing-M105-02, are highlighted in a shaded box. Percentage bootstrap values (1000 trials) of the major nodes are shown. Trees were constructed from CLUSTAL W method in the program MegAlign (DNASTAR, Lasergene Version 8), and viewed with TreeView 1.6.6.

Our preliminary characterization of the Sing-M105-02 and Sing-M100-02 viruses indicated that the etiological agent in the Singapore zoo outbreak was an EMCV.

EMCV-specific primers targeting the VP3/VP1 capsid and 3Dpol genes were able to PCR-amplify products from the viral isolates. These primer sets had been tested on a wide variety of EMCV isolates from different geographic locations, different host species, and at different times [26-28]. Structural proteins such as the VP1 capsid, have been shown to be suitable for phylogenetic analyses within different genera and species of picornaviruses [24,33-41]. Furthermore, analysis using the VP1 capsid could lead to the discovery of a novel variant such as the discovery reported for Hepatitis A [42]. Analysis at the

Table 5 Prevalence of neutralizing antibodies to the Sing-M105-02 isolate in different animals from the Singapore Zoological Garden

\begin{tabular}{|c|c|c|}
\hline Animal & Number tested & Number positive (\% positive) \\
\hline Agile gibbons & 6 & 0 \\
\hline Cape hunting dog & 1 & 0 \\
\hline Capucin Jito & 1 & 0 \\
\hline Capybaras & 10 & $8(80)$ \\
\hline Chimpanzees & 13 & $4(31)$ \\
\hline Colobus monkeys & 3 & 0 \\
\hline Coloque & 1 & 0 \\
\hline Gibbons & 21 & $1(5)$ \\
\hline Howler monkeys & 3 & 0 \\
\hline Japanese monkeys & 2 & 0 \\
\hline Komodo dragons & 2 & 0 \\
\hline Macaques & 19 & 0 \\
\hline Mandrill & 2 & 0 \\
\hline Orang utans & 14 & $7(50)$ \\
\hline Patas monkey & 1 & 0 \\
\hline Pig tail macaques & 2 & 0 \\
\hline Raccoon & 1 & 0 \\
\hline Rats & 2 & $2(100)$ \\
\hline Lemur & 2 & 0 \\
\hline Siamang & 3 & 0 \\
\hline Slow loris & 1 & 0 \\
\hline Spider monkeys & 5 & 0 \\
\hline White nose gueron & 4 & 0 \\
\hline Total & 122 & $22(18)$ \\
\hline
\end{tabular}

VP1 capsid region revealed a maximum of $38.8 \% \mathrm{nt}$ and 33.9\% aa divergence between the Sing-M105-02 and SingM100-02 isolates and existing EMCV strains (Table 3). In addition, aa alignment of Sing-M105-02 and SingM100-02 against other EMCV strains showed considerable variation in two putative neutralization antigenic sites in VP1 (Figure 3), further supporting our hypothesis that these viral isolates can represent a new divergent group of EMCV and possibly a new serotype in the EMCV species.

The picornaviral polymerases or 3Dpol genes, on the other hand, are well conserved during evolution, and have been used as a common marker for comparisons between genera in phylogenetic studies [43-45]. They can also be used to determine the degree of variation between the newly isolated viruses with existing EMCV strains. For example in Foot-and-Mouth-Disease viruses, high sequence divergence found in the 3Dpol regions is an indication of the virus strains diverging from the same isolate [46]. Sequence comparison for Sing-M105-02 and Sing-M100-02 isolates with existing EMCV strains showed a maximum divergence of $24.6 \%$ and $11.3 \%$ at the nt and aa levels respectively (Table 3 ), suggesting that they are indeed highly divergent variants of EMCV.

In addition, the phylogenetic analyses based on complete virus gene sequences (as compared to partial gene sequences) afforded us increased confidence that the Sing-M105-02 and Sing-M100-02 isolates constituted a divergent group of EMCV variants, as they clustered distinctly away from the other lineages of EMCV strains (Figure 4). This high degree of divergence within the EMCV species is perhaps not surprisingly as viruses with RNA genomes are generally reported to have a high rate of mutation [47-49].

Our serological survey of the animal population further suggested that there were at least two virus strains circulating in the Singapore Zoo; the first, an EMCV (Aust)-like virus, and the second, a variant of EMCV. High seropositive rates for the EMCV variant was found in capybaras, chimpanzees, orang utans and two rats caught in baited traps. In addition, neutralizing antibodies to EMCV(Aust) were also found in all except one of the chimpanzee, one orang utan and one of the rats, indicating prior exposure to single or dual infections with the viruses. Although no attempt was made to recover the virus from these animals, we postulated that the EMCV(Aust)-like virus could have been the parental 
virus from which Sing-M105-02 and Sing-M100-02 viruses gradually evolved. Rats have been considered to be the primary host reservoir and disseminators of EMCV, and they have been implicated in other zoological outbreaks of EMCV [2-4,7,9]. The rats could also have initiated the sporadic infections, by spreading both the parental and its variant virus in the zoo. However, this hypothesis remains to be investigated.

\section{Conclusions}

The etiological agent responsible for the outbreak for 2 of the 4 cases of fatal myocarditis in orang utans at the Singapore Zoological Gardens was an EMCV. High divergence in nt sequences of the VP1 capsid and 3Dpol genes as compared to other known EMCV strains, indicated that the outbreak was caused by a highly divergent variant of EMCV and possibly a new serotype of the virus. This is the first report of an EMCV infection in Singapore and South East Asia.

\section{Materials and methods Specimens}

Post-mortem heart and lung tissues were obtained from the two juvenile orang utans. In addition, a total of 122 serum samples from various zoo animals were collected for sero-epidemiological study. These consisted of 6 agile gibbons, 1 cape hunting dog, 1 capuchin monkey, 10 capybaras, 13 chimpanzees, 3 colobus monkeys, 1 coloque monkey, 21 gibbons, 3 howler monkeys, 2 Japanese monkeys, 2 komodo dragons, 19 macaques, 2 mandrills, 14 orang utans, 1 patas monkey, 2 pig-tailed macaques, 1 raccoon, 2 lemurs, 3 siamangs, 1 slow loris, 5 spider monkeys and 4 white nose guenons. Two rats were also captured in a baited trap.

\section{Virus isolation and propagation}

Heart and lung tissues were collected from the postmortem analyses of two juvenile orang utans. The tissues were homogenised in Hank's balanced salt solution and the cellular debris cleared by low-speed centrifugation at about 3,000 to $4,000 \times g$. The homogenates were filtered with a $45 \mu \mathrm{m}$ pore size and the clarified homogenate inoculated onto monolayers of African Green Monkey kidney (Vero) cells (ATCC-CCL81). The infection was carried out at $37^{\circ} \mathrm{C}$ and infected cells were observed for cytopathic cell effect (CPE) under a light microscope. The viruses isolated from the heart and lung tissues were designated as Sing-M105-02 and SingM100-02, respectively. Sing-M105-02, Sing-M100-02 and EMCV(Aust) were propagated in Vero cells in minimal Eagle's medium (MEM) (Invitrogen) supplemented with $5 \%$ fetal calf serum (FCS) (Hyclone, Logan) at $37^{\circ} \mathrm{C}, 5 \%$ $\mathrm{CO}_{2}$ for 3 days. The culture supernatant was then harvested, centrifuged at $4,000 \times g$ and stored at $-80^{\circ} \mathrm{C}$.
EMCV(Aust) strain was imported into Singapore from Dr Peter Kirkland, MacArthur Institute, Australia. The EMCV(Aust) strain was isolated from a rodent in an Australian zoo as reported in Reddacliff et al., [3]. Virus isolates and $\mathrm{EMCV}$ (Aust) were also inoculated into Mardin Darby Canine Kidney (MDCK) cells (ATCC-CCL34) and CPE observed over a few days.

\section{Virus neutralization}

The antiserum was serially diluted in two-folds and mixed with a known titer of either Sing-M105-02 or EMCV (Aust) in equal volume for $1 \mathrm{hr}$ at $37^{\circ} \mathrm{C}$. The antiserumvirus mixtures were next inoculated onto Vero cells seeded in a 96 well formant and examined daily for signs or absence of CPE.

\section{Electron microscopy}

Virus-infected tissue culture fluid was clarified by lowspeed centrifugation at 2,000 to $3,000 \times g$ for $10 \mathrm{~min}$. The virus was pelleted from the supernatant by ultracentrifugation at $159,000 \times g$ for $1.5 \mathrm{~h}$ at $4^{\circ} \mathrm{C}$ and resuspended in PBS [20]. Drops of virus suspension were placed on carbon-formvar coated grids. Negative staining was performed with $2 \%$ phosphotungstic acid, $\mathrm{pH} 7.4$, for $1 \mathrm{~min}$. Grids were examined with a JEOL-1010 electron microscope.

\section{Immunofluorescence assay}

Virus-infected cells were scraped off from a $25 \mathrm{~cm}^{2}$ tissue culture flask at $24 \mathrm{~h}$ pi and washed in phosphate-buffered saline (PBS), $\mathrm{pH} 7.4$, by low speed centrifugation at 2,000 to $3,000 \times g$ for $10 \mathrm{~min}$. The cell pellet was resuspended in $1 \mathrm{ml}$ of PBS and $5 \mu \mathrm{l}$ of cell suspension was distributed into each well of a Teflon-coated slide and air-dried. Cells were fixed in cold acetone for $10 \mathrm{~min}$ and virus antigens detected by immunofluorescence using polyclonal antiEMCV raised in pig as the primary antibody (a gift from Dr Peter Kirkland, MacArthur Institute, Australia). The secondary antibody was goat anti-porcine IgG, conjugated to fluorescein isothiocynate (Chemicon). Evans Blue (Sigma Diagnostics) was used as counter-stain and the slide examined with a Olympus DX51 microscope.

\section{Primers for virus identification and sequencing}

For the initial determination of the virus genus and species, we used a total of 4 sets of PCR primers. Two published primer sets, RotbartFor/RotbartRev and EV1/EV2, both for the detection of enterovirus [24,25], and another two primer sets, P9/P10 (targeting the capsid VP3/VP1 gene) and $\mathrm{P} 1 / \mathrm{P} 2$ (targeting the 3Dpol gene), for the detection of EMCV were selected [13]. The sequences and references of these primers sets are described in Table 1. The primers used for subsequent full genome assembly and 
sequencing were designed by primer walking, and are shown in Table 2.

\section{RNA extraction, CDNA synthesis and PCR}

Viral RNA was extracted from $100 \mu$ of virus-infected Vero cell culture supernatant using the RNeasy Mini Kit (Qiagen) as per the manufacturer's instructions. RNA was eluted in $50 \mu \mathrm{l}$ of RNase-free water. For initial virus identification, the first strand CDNA was synthesized with gene-specific primers $(2 \mu \mathrm{M})$ (Table 1$)$ using the Superscript III First Strand Synthesis System for RT-PCR (Invitrogen, USA) as per the manufacturer's protocol. For virus genome amplification and sequencing, the first strand cDNA was synthesized using using either random hexamers $(50 \mathrm{ng} / \mu \mathrm{l})$ or gene-specific primers $(2 \mu \mathrm{M})$ (Table 2) using the Superscript III First Strand Synthesis System for RT-PCR (Invitrogen, USA) as per the manufacturer's protocol.

For PCR, $2 \mu \mathrm{l}$ of each viral cDNA sample was amplified in a $50 \mu \mathrm{l}$ reaction mixture $(33.5 \mu \mathrm{l}$ RNase-free water, $5 \mu \mathrm{l}$ 10x High Fidelity (HiFi) PCR Buffer, $5 \mu \mathrm{l} 2 \mu \mathrm{M}$ dNTPs, $2 \mu \mathrm{l} 50 \mathrm{mM} \mathrm{MgSO} 4,1 \mu \mathrm{l} 10 \mu \mathrm{M}$ forward primer, $1 \mu \mathrm{l}$ $10 \mu \mathrm{M}$ reverse primer, $0.5 \mu \mathrm{l} 50 \mathrm{U} / \mu \mathrm{l} \mathrm{HiFi} \mathrm{Platinum} \mathrm{Taq).}$ Thermal cycling conditions included initial denaturation at $95^{\circ} \mathrm{C}$ for $5 \mathrm{~min}$; followed by 45 cycles of $95^{\circ} \mathrm{C}$ for $30 \mathrm{~s}$, $45^{\circ} \mathrm{C}$ for $30 \mathrm{~s}, 68^{\circ} \mathrm{C}$ for $2 \mathrm{~min}$; and a final extension step of $68^{\circ} \mathrm{C}$ for $10 \mathrm{~min}$. Touchdown PCR was also performed in several instances to improve PCR amplification specificity.

To obtain the $3^{\prime}$ end sequence of the virus, the GeneRacer kit and core module primers (Invitrogen, USA) were employed as per the manufacturer's instructions. We were unable to obtain about $200 \mathrm{nt}$ of the virus 5' UTR sequence despite numerous attempts using the GeneRacer kit, other reverse transcriptases, DNA polymerases, PCR additives (such as DMSO and betaine), and various PCR thermocycling conditions.

\section{Sequencing and phylogenetic analysis}

PCR products were resolved on 1-2\% agarose gels (depending on amplicon size), and the subsequent PCR clean-up and sequencing of the amplicons were performed by AITbiotech (Singapore) using BigDye chemistry (Life Technologies, USA). In brief, the genomes of EMCV isolates Sing-M100-02 and Sing-M105-02 were determined from a series of PCR amplicons that contained overlapping cDNA fragments. Each gene region was sequenced at least two times. Raw sequences were first assembled and aligned with the reference EMCV Mengo $M$ virus genome (GenBank accession number L22089) using the SeqMan Pro software found in the Lasergene Version 8 (DNASTAR, USA).

Final nt sequences were aligned against other strains of EMCV and picornaviruses using the Clustal W method as implemented in the MegAlign program (DNASTAR, USA). Percent identity and phylogenetic trees were constructed for the entire ORF as well as for individual genes coding for the various proteins at the nt level and neighborjoining trees were constructed after alignment by the same program. The consistency and robustness of tree topology were bootstrapped using 1000 trials and a seed of 111. The TreeView X 1.6.6 program [50] was used to visualize trees.

\section{Nucleotide sequence accession numbers}

The partial sequence data for the VP3/VP1 genes have been deposited in GenBank under the accession numbers AF525466 for Sing-M105-02 and AY162280 for Sing-M100-02. For the partial 3Dpol genes, the nt sequences were deposited under the accession numbers AF510055 for Sing-M105-02, and AY162279 for SingM100-02. The full virus genome sequences (excluding about 200 nt from the $5^{\prime}$ end) have been deposited in GenBank under accession numbers KC310737 for Sing-M100-02, and KC310738 for Sing-M105-02.

\section{Competing interests}

The authors declare that they have no competing interests.

\section{Authors' contributions}

DS-YY, JEL, JCWL, EASL and HCT performed the laboratory experiments. SO performed the clinical assessment. CJF performed the necropsy and sampling. CJF, Y-NL and M-LS performed the virus isolation. B-HT, M-LN, E-EO, K-PC, SO and CJF conceived the study. B-HT and DS-YY were involved in the data analysis and manuscript writing. All authors read and approved the final manuscript.

\section{Acknowledgements}

We thank Dr Cheng Wen-Haur from the Singapore Zoological Gardens, and Dr Paulo Martelli (now the head veterinarian of the Hong Kong Ocean Park), for their assistance in the coordination of sera collection from the zoo animals. We also thank Dr Peter Kirkland, from the MacArthur Institute, Australia, for his gifts of polyclonal antibodies to EMCV, as well as the strain of EMCV(Aust). This project was funded by the Ministry of Defence, Agri-Food and Veterinary Authority of Singapore, and National Environmental Agency, Singapore.

\section{Author details}

'Defence Medical and Environmental Research Institute, DSO National Laboratories, \#13-00, 27 Medical Drive, Buona 117510, Singapore. ${ }^{2}$ School of Biological Sciences, Nanyang Technological University, Nanyang, Singapore. ${ }^{3}$ Agri-Food and Veterinary Authority of Singapore, Singapore, Singapore. ${ }^{4}$ Department of Pathology, Singapore General Hospital, Changi, Singapore. ${ }^{5}$ Department of Microbiology, National University of Singapore, Singapore, Singapore. ${ }^{6}$ Duke-NUS GMS, National University of Singapore, Singapore, Singapore. ${ }^{7}$ Wildlife Reserves Singapore, Singapore, Singapore. ${ }^{8}$ Saw Swee Hock School of Public Health, National University of Singapore, Singapore, Singapore. ${ }^{9}$ Department of Civil and Environmental Engineering, National University of Singapore, Singapore, Singapore.

Received: 10 June 2013 Accepted: 24 July 2013

Published: 2 August 2013

\section{References}

1. Jones P, Cordonnier N, Mahamba C, Burt FJ, Rakotovao F, Swanepoel R, André C, Dauger S, Bakkali Kassimi L: Encephalomyocarditis virus mortality in semi-wild bonobos (Pan panicus). J Med Primatol 2011, 40:157-163.

2. Hubbard GB, Soike KF, Butler TM, Carey KD, Davis H, Butcher WI, Gauntt CJ: An Encephalomyocarditis virus epizootic in a baboon colony. Lab Anim Sci 1992, 42:233-239. 
3. Reddacliff LA, Kirkland PD, Hartley WJ, Reece RL: Encephalomyocarditis virus infections in an Australian zoo. J Zool Wild Med 1997, 28:153-157.

4. Canelli E, Luppi A, Lavazza A, Lelli D, Sozzi E, Martin AM, Gelmetti D, Pascotto E, Sandri C, Magnone W, Cordioli P: Encephalomyocarditis virus infection in an Italian zoo. Virol J 2010, 7:64

5. Masek-Hammerman K, Miller AD, Lin KC, MacKey J, Weissenbock $H$, Gierbolini L, Burgos A, Perez H, Mansfield KG: Epizootic myocarditis associated with Encephalomyocarditis virus in a group of rhesus macaques (macaca mulatta). Vet Path 2012, 49:386-392.

6. Citino SB, Gaskin HJH, Wickham DJ: Fatal Encephalomyocarditis virus infection in Sumatran orangutan (Pongo pygmaeus abelii). J Zoo Wildl Med 1998, 19:214-218.

7. Wells SK, Gutter AE, Soike KF, Baskin GB: Encephalomyocarditis virus: epizootic in a zoological collection. J Zool Wild Med 1989, 20:291-296.

8. Simpson CF, Lewis AL, Gaskin JM: Encephalomyocarditis virus infection of captive elephants. J Am Vet Med Assoc 1977, 171:902-905.

9. Grobler DG, Raath JP, Braack LE, Keet DF, Gerdes GH, Barnard BJ, Kriek NP, Jardine J, Swanepoel R: An outbreak of Encephalomyocarditis-virus infection in free-ranging African elephants in the Kruger National Park. Onderstepoort J Vet Res 1995, 62:97-108

10. van Sandwyk JH, Bennett NC, Swanepoel R, Bastos AD: Retrospective genetic characterisation of Encephalomyocarditis viruses from African elephant and swine recovers two distinct lineages in South Africa. Vet Microbiol 2013, 162:23-31.

11. Krylova RI, Dzhikidze EK: Encephalomyocarditis in monkeys. Bull Exp Biol Med 2005, 139:355-359.

12. Joo HS: Encephalomyocarditis virus. In Diseases of Swine. Edited by Leman AD, Straw BE, Mengeling WL, Mengeling S, D'Allaire S, Taylor DJ. London: Wolfe Publishing; 1992:257-262.

13. Koenen F, Vanderhallen H, Papadopoulos O, Billinis CP, Paschaleri-Papadopoulou E, Brocchi E, De Simone F, Carra E, Knowles NJ: Comparison of the pathogenic, antigenic and molecular characteristics of two Encephalomyocarditis virus (EMCV) isolates from Belgium and Greece. Res Vet Sci 1997, 62:239-244.

14. Paschaleri-Papadopoulou E, Axiotis I, Laspidis C: Encephalomyocarditis of swine in Greece. Vet Rec 1990, 124:364-365

15. Sidoli L, Barigazzi G, Foni E, Marcato PS, Barbieri G: Encephalomyocarditis (EMC) due to Cardiovirus in Po Valley swines: preliminary observations, clinical aspects, virus isolation, characterization and experimental transmission. Selozoine Vet 1989, 30:249-260.

16. Maurice $H$, Nielen M, Brocchi E, Nowotny N, Kassimi LB, Billinis C, Loukaides P, O'Hara RS, Koenen F: The occurrence of Encephalomyocarditis virus (EMCV) in European pigs from 1990 to 2001. Epidemiol Infect 2005, 133:547-557.

17. Park NY, Ri CY, Chung CY, Kee HY, Bae SY: Pathological findings on Encephalomyocarditis virus infections of swine in Korea. Korea J Vet Res 1992, 32:99-109.

18. Hu DG, Chan CH, Shieh WY, Chang CS: Epidemiological studies of swine Encephalomyocarditis virus infection, Research report - animal industry research institute, Taiwan Sugar Corporation. 1993:149-154. 1992/93.

19. Miyagi J, Tsuhako K, Kinjo T, Iwamasa T, Kamada Y, Kinju T, Koyanagi Y: Coxsackievirus B4 myocarditis in an orangutan. Vet Path 1999, 36:452-456

20. Gajdusek DC: Encephalomyocarditis virus infection in childhood Pedriatrics 1955, 16:902-907.

21. Dick GWA, Best AM, Haddow AJ, Smithburn KC: Mengo encephalomyelitis, a hitherto unknown virus affecting man. Lancet 1948, 252:286-289.

22. Oberste MS, Gotuzzo E, Blair P, Nix WA, Ksiazek TG, Comer JA, Rollin P, Goldsmith CS, Olson J, Kochel TJ: Human febrile illness caused by Encephalomyocarditis virus infection, Peru. Emerg Infect Dis 2009, 15:640-646.

23. Knowles NJ, Hovi T, Hyypiä T, King AMQ, Lindberg AM, Pallansch MA, Palmenberg AC, Simmonds P, Skern T, Stanway G, Yamashita T, Zell R: Picornaviridae. In Virus taxonomy: classification and nomenclature of viruses: ninth report of the international committee on taxonomy of viruses. Edited by King $A M Q$, Adams MJ, Carstens EB, Lefkowitz EJ. San Diego: Elsevier; 2012:855-880.

24. Oberste MS, Maher, Flemister MR, Marchetti G, Kilpatrick DR, Pallansch MA: Comparison of classic and molecular approaches for the identification of untypeable enteroviruses. J Clin Microbiol 2000, 38:1170-1174.

25. Rotbart AR: PCR amplification of enteroviruses. In PCR protocols: a guide to methods and amplifications. Edited by Innis MA, Gelfand DH, Sninsky JJ, White TJ. San Diego: Academic Press; 1990:372-377.

26. Koenen F, Vanderhallen H, Dickinson ND, Knowles NJ: Phylogenetic analysis of European Encephalomyocarditis viruses: comparison of two genomic regions. Arch Virol 1999, 144:893-903.
27. Vanderhallen $\mathrm{H}$, Koenen F: Rapid diagnosis of Encephalomyocarditis virus infections in pigs using a reverse transcription-polymerase chain reaction. J Virol Met 1997, 66:83-89.

28. Vanderhallen $\mathrm{H}$, Koenen $\mathrm{F}$ : Identification of Encephalomyocarditis virus in clinical samples by reverse transcription-PCR followed by genetic typing using sequence analysis. J Clin Microbiol 1998, 36:3463-3467.

29. Philipps A, Dauber M, Groth M, Schirrmeier H, Platzer M, Krumbholz A, Wutzler $P$, Zell R: Isolation and molecular characterization of a second serotype of the Encephalomyocarditis virus. Vet Microbiol 2012, 161:49-57.

30. Luo M, Vriend G, Kamer G, Minor I, Arnold E, Rossmann MG, Boege U, Scraba DG, Duke GM, Palmenberg AC: The atomic structure of Mengo virus at 3.0 A resolution. Science 1987, 235:182-191.

31. Boege U, Kobasa D, Onodera S, Parks GD, Palmenberg AC, Scraba DG Characterization of Mengo virus neutralization epitopes. Virology 1991, 181:1-13.

32. Denis $\mathrm{P}$, Liebig HD, Nowotny N, Billinis C, Papadopoulos O, O'Hara RS, Knowles NJ, Koenen F: Genetic Encephalomyocarditis virus (EMCV) isolates. Vet Microbiol 2006, 113:1-12.

33. Zimmerman JJ: Encephalomyocarditis. In CRC handbook series in zoonoses Section B: viral zoonoses. Edited by Beran GW, Steele JH. Boca Raton: CRC Press; 1994:423-436.

34. Brown BA, Oberste MS, Alexander JP Jr, Kennett ML, Pallansch MA: Molecular epidemiology and evolution of enterovirus 71 strains isolated from 1970 to 1998. J Virol 1999, 73:9969-9975.

35. Haydon DT, Bastos AD, Knowles NJ, Samuel AR: Evidence for positive selection in foot-and-mouth disease virus capsid genes from field isolates. Genetics 2001, 157:7-15.

36. McMinn P, Lindsay K, Perera D, Chan HM, Chan KP, Cardosa MJ: Phylogenetic analysis of enterovirus 71 strains isolated during linked epidemics in Malaysia, Singapore, and Western Australia. J Virol 2001, 75:7732-7738

37. Mulders MN, Salminen M, Kalkkinen N, Hovi T: Molecular epidemiology of coxsackievirus B4 and disclosure of the correct VP1/2A(pro) cleavage site: evidence for high genomic diversity and long-term endemicity of distinct genotypes. J Gen Virol 2000, 81:803-812

38. Norder H, Bjerregaard L, Magnius LO: Homotypic echoviruses share aminoterminal VP1 sequence homology applicable for typing. J Med Virol 2001, 63:35-44.

39. Oberste MS, Maher K, Kilpatrick DR, Pallansch MA: Molecular evolution of the human enteroviruses: correlation of serotype with VP1 sequence and application to Picornavirus classification. J Virol 1999, 73:1941-1948.

40. Oberste MS, Schnurr D, Maher K, al-Busaidy S, Pallansch MA: Molecular identification of new picornaviruses and characterization of a proposed enterovirus 73 serotype. J Gen Virol 2001, 82:409-416.

41. Santti J, Harvala H, Kinnunen L, Hyypia T: Molecular epidemiology and evolution of coxsackievirus A9. J Gen Virol 2000, 81:1361-1372.

42. Costa-Mattioli M, Cristina J, Romero H, Perez-Bercof R, Casane D, Colina R, Garcia L, Vega I, Glikman G, Romanowsky V, Castello A, Nicand E, Gassin M, Billaudel S, Ferre V: Molecular evolution of hepatitis A virus: a new classification based on the complete VP1 protein. J Virol 2002, 76:9516-9525.

43. Koonin EW: The phylogeny of RNA-dependent RNA polymerases of positive-strand RNA viruses. J Gen Virol 1991, 72:2197-2206.

44. Rodrigo MJ, Dopazo J: Evolutionary analysis of the picornavirus family. J Mol Evol 1995, 40:362-371.

45. Palmberg AC, Kirby EM, Janda MR, Drake NL, Duke GM, Potratz KF, Collett MS: The nucleotide and deduced amino acid sequences of the Encephalomyocarditis viral polyprotein coding region. Nucleic Acids Res 1984, 12:2969-2985.

46. Villaverde A, Martinez-Salas E, Domingo E: 3D gene of foot-and-mouth disease virus: Conservation by convergence of average sequences. $\mathrm{J} \mathrm{Mol}$ Biol 1988, 204:771-776.

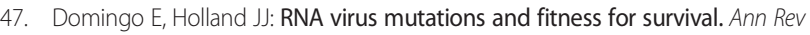
Microbiol 1997, 51:151-178.

48. Domingo E: Viruses at the edge of adaptation. Virology 2000, 270:251-253.

49. Lauring AS, Andino R: Quasispecies theory and the behavior of RNA viruses. PLoS Pathog 2010, 6:e1001005.

50. Page RDM: TREEVIEW: an application to display phylogenetic trees on personal computers. Comp App/ Biosci 1996, 12:357-358.

doi:10.1186/1743-422X-10-248

Cite this article as: Yeo et al.: A highly divergent Encephalomyocarditis virus isolated from nonhuman primates in Singapore. Virology Journal 2013 10:248. 